\title{
Interfacial Gap Assessment of Two Dental Adhesives and Polymer-Based Resin Composites Using Cross-Polarization Optical Coherence Tomography
}

Turki A. Bakhsh ${ }^{\mathrm{a}^{*}}$, Halah M. Alturkstani ${ }^{\mathrm{b}}$, Razan N. Alharbi ${ }^{\mathrm{b}}$, Hind J. Alrefai ${ }^{\mathrm{b}}$, Tahani O. Badeeb ${ }^{\mathrm{b}}$, Nour H. Altouki ${ }^{\mathrm{b}}$, Ahmed O. Jamleh ${ }^{\mathrm{c}}$

aDepartment of Operative Dentistry, Faculty of Dentistry, King Abdulaziz University, P.O. Box 80209, Jeddah 215-89, Saudi Arabia.

${ }^{\text {b} F a c u l t y ~ o f ~ D e n t i s t r y, ~ K i n g ~ A b d u l a z i z ~ U n i v e r s i t y, ~ P . O . ~ B o x ~ 80209, ~ J e d d a h ~ 215-89, ~ S a u d i ~ A r a b i a . ~}$

${ }^{\mathrm{c}}$ College of Dentistry, King Abdullah International Medical Research Center / King Saud bin Abdulaziz University for Health Sciences - National Guard Health Affairs, P.O. Box 22490 Riyadh, 11426, Saudi Arabia

* Indicate Corresponding Author:

Turki A. BAKHSH

Department of Operative Dentistry

King Abdulaziz University

P.O. Box 80209, Jeddah 215-89

Saudi Arabia

Tel: 966-6401000; Ext: 20326

Email: taabakhsh@kau.edu.sa 
1. Turki A. Bakhsh, Associate Professor, Faculty of Dentistry, King Abdulaziz University. taabakhsh@kau.edu.sa

2. Halah M. Alturkstani, General dentist, Faculty of Dentistry, King AbdulAziz University. h.m.tur@hotmail.com

3. Razan N. Alharbi, General dentist, Faculty of Dentistry, King AbdulAziz University. razan.n.alharbii@gmail.com

4. Hind J. Alrefai, General dentist, Faculty of Dentistry, King AbdulAziz University. Hind.alrefai@gmail.com

5. Tahani O. Badeeb, General dentist, Faculty of Dentistry, King AbdulAziz University. tahaniob@hotmail.com

6. Nour H. Altouki, General dentist, Faculty of Dentistry, King AbdulAziz University. nouraltouki@gmail.com

7. Ahmed Jamleh, Associate professor, College of Dentistry, King Abdullah International Medical Research Center / King Saud bin Abdulaziz University for Health Sciences. aojamleh@gmail.com 


\section{ABSTRACT}

Objectives: The current study aimed to compare the adaptation of the restored class-I cavities with two self-etch adhesives bonded to two resin composite using crosspolarization optical coherence tomography (CP-OCT). Materials and Methods: Cylindrical class-I cavities were prepared on twenty, extracted human premolars. Two self-etch adhesives; Clearfil SE bond 2 (SE; Kuraray Noritake Dental, Japan) and Bond Force (Palfique Bond) adhesive (PL; Tokuyama Dental, Japan) were used in this study that were bonded to either resin composites materials; Herculite XRV microhybrid dental composite (HRV; Kerr, Italy) or Estelite Alpha composite (ESA; Tokuyama Dental, Japan). The specimens were divided into four groups ( $\mathrm{n}=5)$; SE-HRV, SE-ESA, PL-HRV and PL-ESA. All specimens were varnished and stored in distilled water for 24h. Then, they were submerged in a contrasting medium. After that, all groups were optically imaged under CP-OCT at every $250 \mu \mathrm{m}$ interval distance. Later, image binarization and gap quantification were carried out using Image analysis software. Result: There was a significant difference between all the groups except between SEESA and PL-ESA $(\mathrm{p}=0.51)$. The highest median gap $\%$ was seen in PL-HRV group followed by SE-ESA, PL-ESA and SE-HRV. Conclusion: Other than composite filler loading and adhesive formula, the interactions of the adhesive and composite copolymers have great influence on composite adaptation.

\section{Keywords}

Adhesive, Dentin, Composite, Adaptation, Tooth, Optical coherence tomography, Gap 


\section{Introduction}

Today one of the most important advances in clinical dentistry is tooth-colored direct restorations [1]. Nowadays different composite materials and different adhesive systems are available in the market.

In spite of the great advantages of resin composite, it still has some drawbacks. Microleakage is considered a major one, which can be defined as the gap between the restoration and the tooth structure where fluid and bacteria can penetrate and stagnate $[2,3]$. The presence of these gaps at the restoration margin may lead to hypersensitivity, secondary caries and bacterial invasion that could result in restoration failure. Additionally, interfacial gap formation at the restoration margins could be related to the polymerization shrinkage and Configuration factor (C-factor) or poor manipulation of the material [4].

There are several testing methods had been introduced to assess composite adaptation and gap formation at tooth-resin interface [1]. Conventional methods; such as tactile probes and x-rays, have limitations in evaluating early failure and accurately monitoring a suboptimal marginal interface [5]. Although scanning electron microscopes and transmission electron microscope enabled examination of the tooth-resin interface at submicron scale, they are destructive methods and requires sample preparation and crosssectioning before examination. Cone-beam computed tomography and computed tomography are non-destructive imaging methods. However, the high radiation dose limits their applications. Besides, sometimes the thick bonding layer could be misinterpreted as recurrent caries in these imaging methods. Recently, optical coherence tomography (OCT) is one of the established testing methods to evaluate the adaptation of composite material 
[6].

OCT in dentistry has been introduced as a non-invasive cross-sectional imaging technique. It uses low-coherence interferometry to produce a two-dimensional image of optical scattering from internal tissue microstructures in a way that is analogous to ultrasonic pulse-echo imaging. It has longitudinal and lateral spatial resolutions of a few micrometers [7]. In microleakage studies, it is considered a conservative approach that makes it superior to dye penetration test and ground sectioning technique that necessitate tooth sectioning to expose tooth-resin interface [1].

Many studies supported and discussed the multiuse of the OCT system. Several investigators used OCT in imaging hard and soft dental tissues [8-10]. In addition, it has been used to image dental caries, biofilms and biomaterials interaction with dental tissues [11-14]. In 2011, Bakhsh et al. concluded that OCT could provide further information on the effectiveness and performance of dental composites and restoration techniques in the quantitative assessment of dental restorations [6]. Moreover, Alsayed et al. concluded that OCT was used effectively and non-invasively in the determination of the resin composite coating integrity and enamel changes [15]. Another report stated that OCT could be used in research settings as well as in clinical use [16].

Unlike in enamel, bonding to dentin is complicated and requires considerable attention [17-19]. Introduction of the self-etch adhesive system was a significant advancement in dentistry to overcome the drawbacks of the total-etch adhesive system. Self-etch adhesives are known as simplified bonding technique and less technique sensitive due to the absence of acid etching and water-rinsing steps [18]. 
The self-etch adhesives are categorized into two-step and one-step self-etch adhesives. Regardless of the number of the steps, this adhesive system consist of acidic primers and bonding adhesive. In two-step self-etch adhesives, the primer and bonding are in separate bottles, while they are combined in a single bottle in one-step adhesives [20]. It is worth mentioning that the etching effect of self-etch adhesives is related to the acidic functional monomers that interact with the mineral component of tooth substrate [21]. Although, these adhesives have a direct influence on composite adaptation during cavity restoration, they are undetectable by conventional invasive imaging techniques. Recent studies showed the usefulness of cross-polarization OCT (CP-OCT) in measuring gaps under composite restorations [22-24].

In this study, our aim was to optically assess the adaptation of two different adhesives bonded to two resin composites using CP-OCT.

\section{Materials and methods}

\subsection{Material used:}

In this in vitro study, two resin-based dental adhesive material; Clearfil SE bond 2, a twostep, self-etch, light-cure bonding adhesive (SE; Kuraray Noritake Dental, Japan) and Bond Force (Palfique Bond) a one-step, self-etch, light-cure bonding system (PL; Tokuyama Dental, Japan) were used along with two resin-based dental restorative materials; Herculite XRV microhybrid dental composite (HRV; Kerr, Italy) and Estelite alpha composite (ESA; Tokuyama Dental, Japan). The materials used are listed in table-1 (Table-1). 
Table 1: List of the composition of adhesive and Composite used in this study.

\begin{tabular}{|c|c|c|c|}
\hline $\begin{array}{c}\text { Material } \\
\text { (Manufacture) } \\
\text { Lot No. }\end{array}$ & Code & Composition & $\begin{array}{c}\text { Fillers volume } \\
\text { (Vol\%) } \\
\text { Fillers Size }\end{array}$ \\
\hline $\begin{array}{l}\text { Clearfil SE } \\
\text { bond } 2 \\
\text { Two-step self- } \\
\text { etch } \\
\text { (Kuraray } \\
\text { Noritake) } \\
\text { 5L0010 }\end{array}$ & SE & $\begin{array}{ll}\text { - } & \text { Primer: } \\
\text { - } & \text { 10-MDP } \\
\text { - } & \text { HEMer } \\
\text { - } & \text { Hydrophilic Dimethacrylate } \\
\text { - } & \text { NQ } \\
\text { - } & \text { Bond: } \\
\text { - } & \text { Bis-GMA } \\
\text { - } & \text { HEMA } \\
\text { - } & \text { Hydrophonol p-toluidine } \\
\text { - } & \text { Colloidal silica } \\
\text { - } & \text { Dl-Camphorquinone } \\
\text { - } & \text { Accelerators } \\
\text { - } & \text { N, N- Diethanol p-toluidine }\end{array}$ & - \\
\hline $\begin{array}{l}\text { Bond Force } \\
\text { (Palfique bond) } \\
\text { One-step self- } \\
\text { etch } \\
\text { (Tokuyama } \\
\text { Dental) } \\
\text { 028E26 }\end{array}$ & PL & $\begin{array}{ll}- & \text { 3D-SR } \\
- & \text { HEMA } \\
- & \text { Bis-GMA } \\
\text { - } & \text { TEGDMA } \\
\text { - } & \text { Glass fillers } \\
\text { - } & \text { Isoproinitiators } \\
- & \text { Water } \\
& \text { Sodium Fluoride }\end{array}$ & - \\
\hline $\begin{array}{c}\text { Herculite XRV } \\
\text { (Kerr) } \\
5162588\end{array}$ & HRV & $\begin{array}{ll}\text { - } & \text { Methacrylate Ester Monomers } \\
\text { - } & \text { 7,7,9(or 7,9,9)-trimethyl-4, 13-dioxo-3,14-dioxa-5, 12- } \\
& \text { diazahexadecane-1, 16-diyl bismethacrylate } \\
\text { - } & \text { 1,6-hexanediyl bismethacrylate } \\
\text { - } & \text { 2,2'-ethylenedioxydiethyl dimethacrylate } \\
\text { - } & \text { hexamethylene diacrylate } \\
\text { - } & \text { Inert minethoxysilylpropyl methacrylate } \\
\text { - } & \text { Activaters and stabilizers } \\
\text { - } & \text { Inorganic filler }\end{array}$ & $\begin{array}{l}\text { - } \quad(59 \%) \\
\text { - } \quad 0.6 \mu \mathrm{m}\end{array}$ \\
\hline $\begin{array}{c}\text { Estelite } \\
\text { Alpha } \\
\text { (Tokuyama } \\
\text { Dental) }\end{array}$ & ESA & $\begin{array}{ll}\text { - } & \text { Bis-GMA } \\
\text { - } & \text { Triethylene glycol dimethacrylate } \\
\text { - } & \text { Silica-zirconia spherical filler } \\
& \text { Composite filler }\end{array}$ & $\begin{array}{l}\text { - } \quad(71 \%) \\
\text { - } \quad 0.2 \mu \mathrm{m}\end{array}$ \\
\hline
\end{tabular}

Abbreviation: HEMA: 2-Hydroxyethyle Methacrylate; Bis-GMA: Bisphenol A Diglycidyl methacrylate; 10MDP: 10-Methacryloyloxydecyl dihydrogen phosphate; CQ: Camphorquinone; 3D-SR: Methacryloyloxyalkyl acid phosphate; TEGDMA: Triethyleneglycol dimethacrylate. 


\subsection{Teeth specimen, cavity preparation, and restoration:}

In this experiment, the collection and usage of the extracted human premolar teeth were subjected to the guidelines of the Ethics Committee of King Abdulaziz University that was in accordance with the principles of the Declaration of Helsinki.

The forty non-carious teeth were visually examined for any soft tissue remnant followed by scaling to clean the teeth. Reduction of the coronal cusps of each specimen by a high-speed diamond bur to obtain a flat enamel occlusal surface. After that, root trimming was done using a model trimmer for all teeth.

Then, cylindrical class-I cavity preparation was prepared on the occlusal surface $(1.5 \mathrm{~mm}$ in depth $\times 4 \mathrm{~mm}$ in diameter) using wheel diamond bur. After cavity preparation, the specimens were divided randomly into four groups. Each group $(n=10)$ was bonded with one of the adhesives (SE, PL) and light-cured according to the manufacturer instructions. Then, one of the resin composite (HRV, ESA) was used to restore the prepared cavities in bulk filling technique and light-cured according to the manufacturer's recommendations using LED light cure $\left(1200 \mathrm{~mW} / \mathrm{cm}^{2}\right)$. Finally, the specimen was embedded in self-cure epoxy resin except the occlusal surface and coated all around with a double layer of polish nail varnish, away from the toothcomposite margins by $0.5 \mathrm{~mm}$. Schematic illustration for the methodology is showed in Figure 1. 


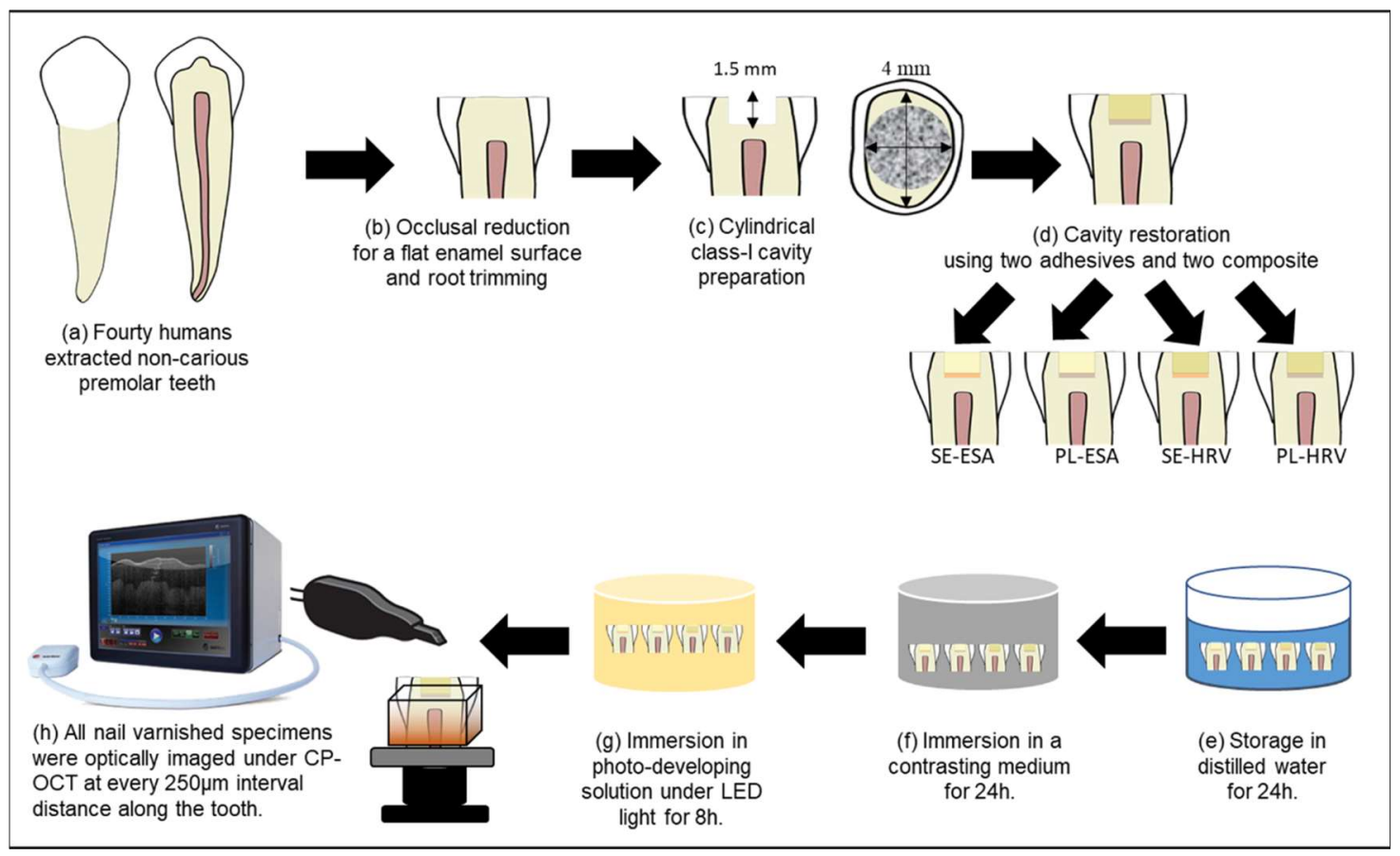

Figure 1: Schematic illustration that shows the methodology of the study.

\subsection{Contrasting agent preparation:}

Protocol of preparation of Ammonical silver nitrate solution as a contrasting agent was carried out as described previously [22]. In a dark room, $25 \mathrm{mg}$ of silver nitrate crystals (Sigma Chemical, USA) were dissolved in $25 \mathrm{ml}$ of distilled water. After that, ammonium hydroxide (Sigma Chemical, USA) was added to titrate the black, dark solution until the point that it turned out to be clear and transparent.

The varnished specimens were stored in distilled water for $24 \mathrm{~h}$. Then, all the specimens were submerged in the silver nitrate solution for $24 \mathrm{~h}$, followed by $8 \mathrm{~h}$ in photo-developing solution under fluorescent light to convert the silver-diamine ions into metallic silver particles. After that, all specimens were washed under distilled water for $30 \mathrm{~s}$. 


\subsection{CP-OCT system and data acquisition:}

The used CP-OCT (IVS-300, Santec, Japan) was connected to a portable PC and equipped with a handheld probe that projects diode laser with high scanning rate $(30 \mathrm{kHz})$ and continuous wavelength centered near $1310 \mathrm{~nm}$, with a wavelength range $100 \mathrm{~nm}$. The lateral resolution was around $30 \mu \mathrm{m}$ and $12 \mu \mathrm{m}$ for the axial resolution, while the system sensitivity is $\geq 95 \mathrm{~dB}$, and probe output power is within the safety limits defined by American National Standard Institute [25]. The technical specification of the used CP-OCT system is described in table-2 (Table-2). Each specimen was placed on a micrometer stage, and serial tomographic B-scan images were taken by CP-OCT for interfacial assessment at every $250 \mu \mathrm{m}$ (Figure 1). The mechanism of OCT imaging and data acquisition and processing is described elsewhere [25].

Table-2: Technical specifications of the CP-OCT system.

\begin{tabular}{|c|c|}
\hline \multicolumn{2}{|c|}{ Cross-Polarization OCT (CP-OCT; IVS-300, Santec, Japan) } \\
\hline Parameter & Specification \\
\hline Wavelength & $1330 \pm 30 \mathrm{~nm}$ \\
\hline Scan rate & $30 \pm 0.1 \mathrm{kHz}$ \\
\hline Axial resolution & $\leq 12 \mu \mathrm{m}$ (in air) \\
\hline Lateral resolution (Based on Spot size) & $30 \pm 7 \mu \mathrm{m}$ (in air) \\
\hline System sensitivity & $>95 \mathrm{~dB}$ \\
\hline Lateral scan area & $\geq 5 \times 5 \mathrm{~mm}$ \\
\hline Imaging depth & $3 \mathrm{~mm}$ \\
\hline Maximum Output Power & $\geq 1 \mathrm{~mW}$ (Near-infrared Class 1 Laser) \\
\hline
\end{tabular}

\subsection{CP-OCT Image Analysis}

The obtained OCT data were reconstructed into a grayscale image using a plug-in macrofile installed into an image analysis software (ImageJ 1.5m9, National Institutes of Health, USA). 
The reconstructed B-scans were showing the interfacial areas with either a diffuse backscattered reflection in the form of a bright white cluster of pixels that represent gaps or no gap as a low backscattered reflection in the form of dark pixels as we reported previously [22].

OCT Image analyses were carried out in accordance to the previously described protocol (Bakhsh et al. 2012, Bakhsh et al. 2013, Bakhsh et al. 2011). Initially, each grayscale image was divided into three equal horizontal sections. Then, the cavity floor was selected, measured, and converted into a binary image; white and black pixels. In binarization mode, areas with high backscattered reflections were converted into black pixels, which represent microgaps, over a white background. Gap percentage at the pulpal floor of the restoration was calculated by the following equation:

$$
\text { Gap Percentage }=\frac{\text { Gap width }}{\text { Total floor width }} \times 100
$$

\subsection{Statistical analysis:}

Since the Shapiro-Wilk test did not show normal distribution $(\mathrm{p}=0.00)$, a Kruskal-Wallis test was conducted to determine if there were differences in median gap percentages among the tested adhesives. Subsequently, pairwise comparisons were performed using MannWhitney test for multiple comparisons.

\section{Results}

The obtained results in this study are presented in figure 2-5 (Figure 2-5). Upon inspecting the obtained B-scan images, some images showed strong signal intensity at the tooth-resin interface that was demonstrated in a form of bright white cluster of pixels, 
which indicated poor composite adaptation and gap formation at the bonded interface. On the hand, other areas showed low signal intensity with the absence of bright clusters that represent no gap existence or loss of the interfacial seal.

By analyzing the obtained data, it showed a significant difference between all the groups except between SE-ESA and PL-ESA $(\mathrm{p}=0.51)$. The highest median gap $\%$ was seen in PL-HRV group followed by SE-ESA, PL-ESA and SE-HRV (Table-3).

Table-3: Results of the study.

\begin{tabular}{lccc}
\hline Group & & Gap percentage & \\
\cline { 2 - 4 } & Mean (SD) & $\begin{array}{c}\text { Median (25th-75th } \\
\text { percentile) }\end{array}$ & $\begin{array}{c}\text { Mean } \\
\text { rank }\end{array}$ \\
\hline SE-ESA & $2.3(2.8)$ & $1.62(0.68-2.98)^{\mathrm{a}}$ & 72.74 \\
\hline PL-ESA & $7.44(11.1)$ & $0(0-14.86)^{\mathrm{a}}$ & 67.56 \\
\hline SE-HRV & $2.29(5.1)$ & $0(0)^{\mathrm{b}}$ & 47.88 \\
\hline PL-HRV & $53.47(29.1)$ & $56.15(28.57-75.52)^{\mathrm{c}}$ & 133.83 \\
\hline
\end{tabular}

The different superscripts indicate statistically significant differences between groups. 


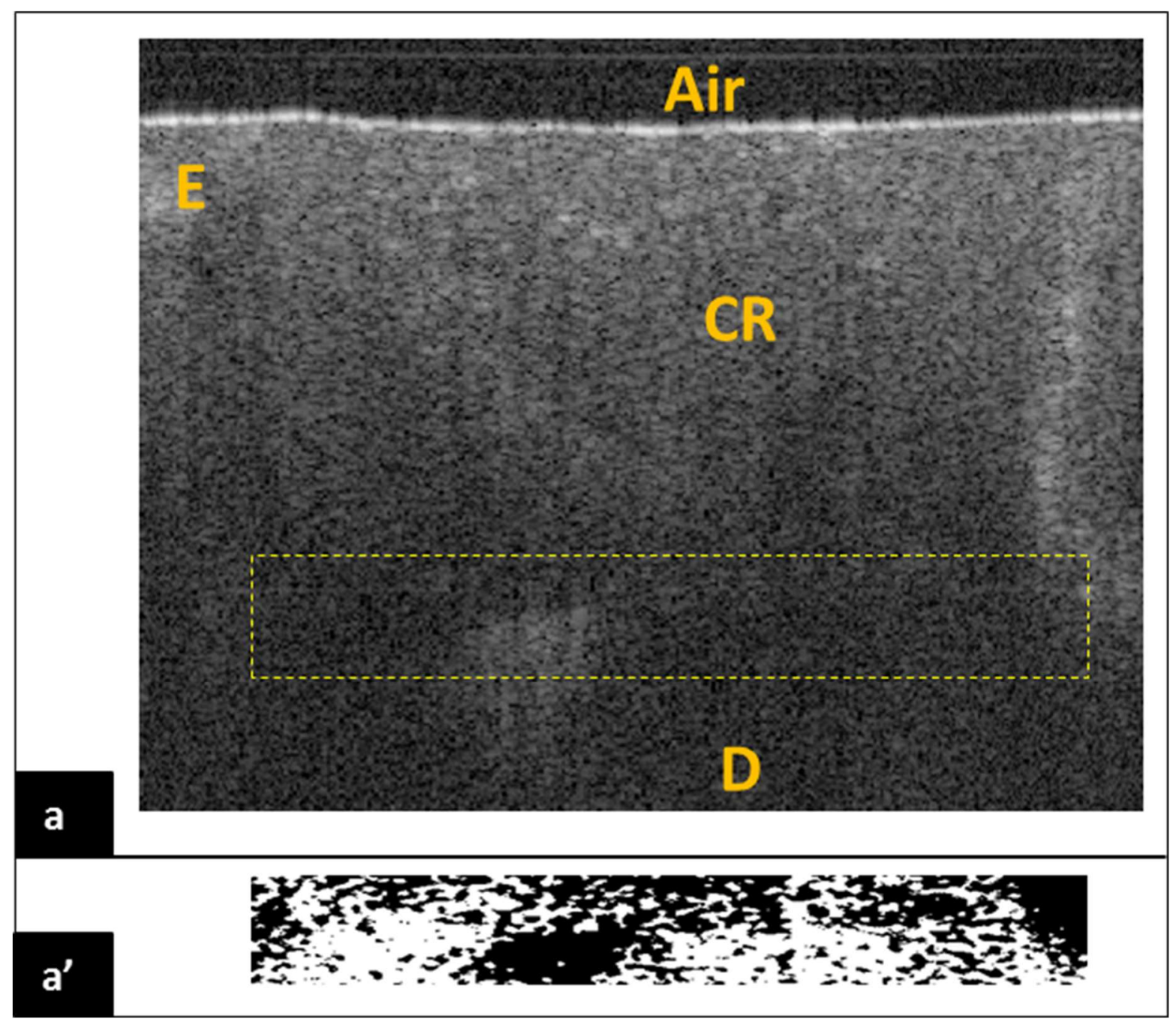

Figure 2. Representative B-scan for SE-ESA group in (a). (a') is a binary image for the dotted box in (a) at the cavity floor. The center of the cavity floor in (a) is showing high signal intensity in a form of bright pixels that was corresponding to the dark pixels in (a'). CR: Composite resin, E: Enamel, D: Dentin. 


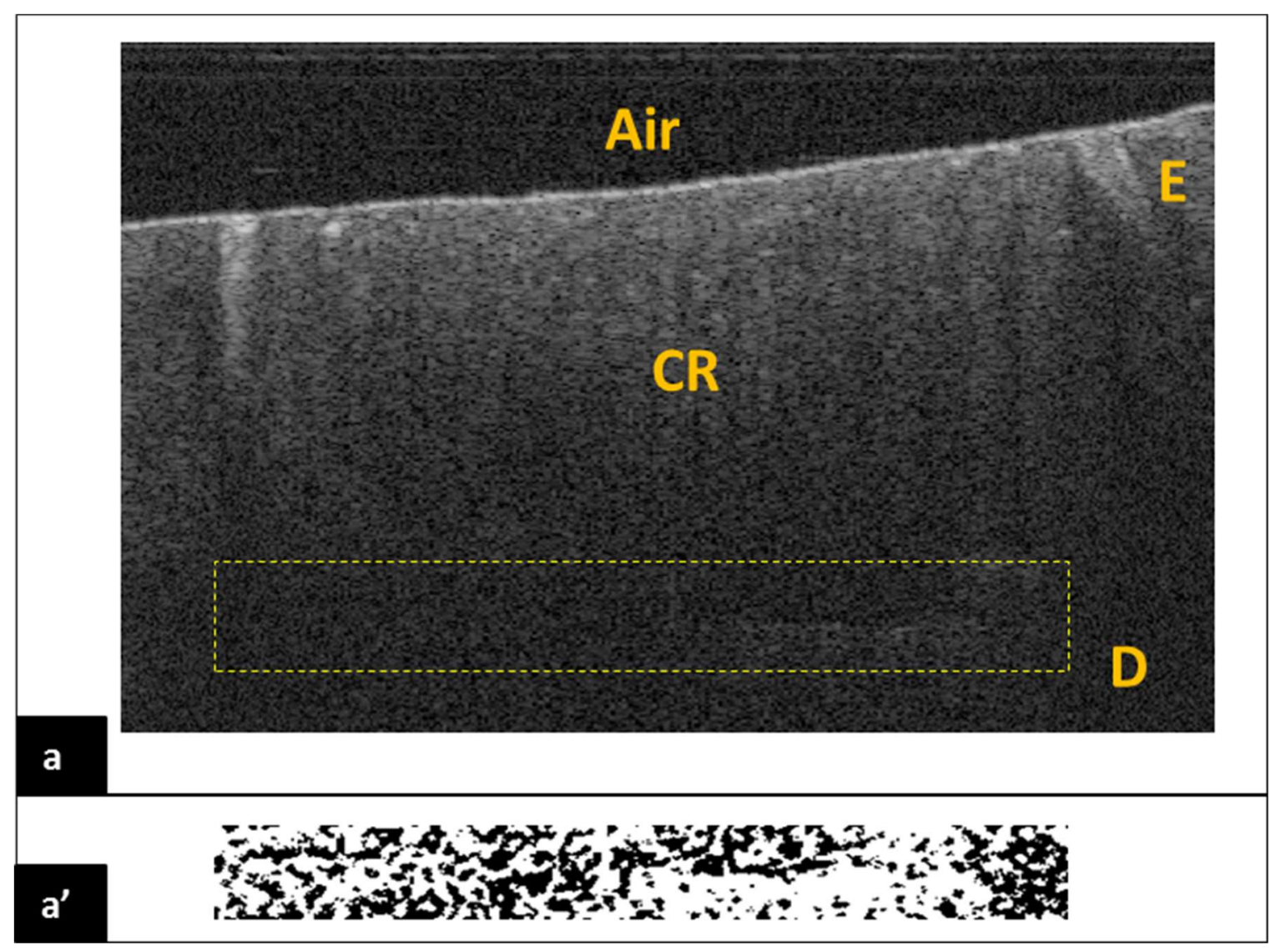

Figure 3. Representative B-scan for PL-ESA group in (a). (a') is a binary image for the dotted box in (a) at the cavity floor. The cavity floor in (a) showed high signal intensity in a form of bright pixels a the right side of the cavity floor that were corresponding to the dark pixels in (a'). CR: Composite resin, E: Enamel, D: Dentin. 


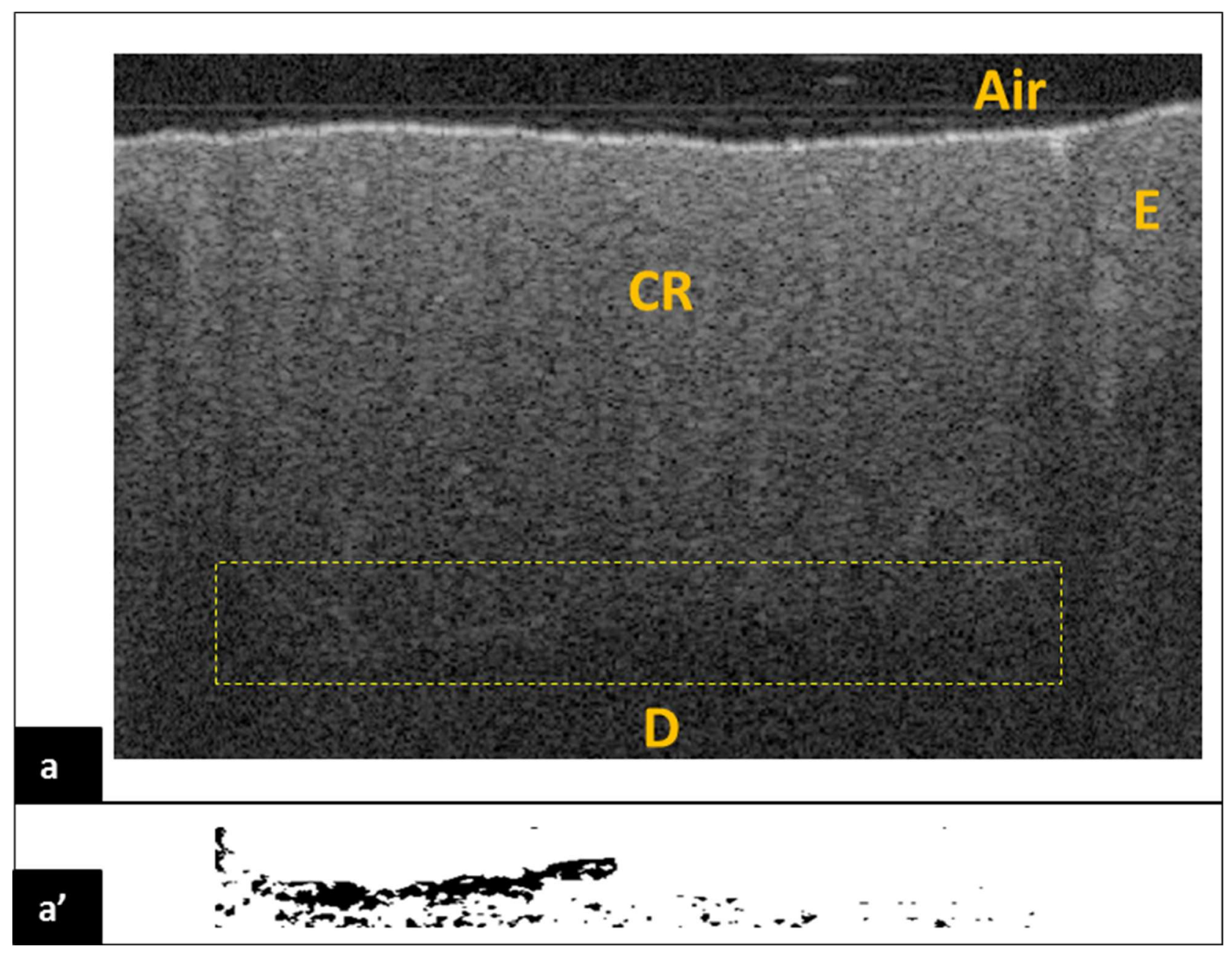

Figure 4. Representative B-scan for SE-HRV group in (a). (a') is a binary image for the dotted box in (a) at the cavity floor. The cavity floor in (a) showed high signal intensity in a form of bright pixels at the left side of the cavity that were corresponding to the continuous band of dark pixels in (a'). CR: Composite resin, E: Enamel, D: Dentin. 


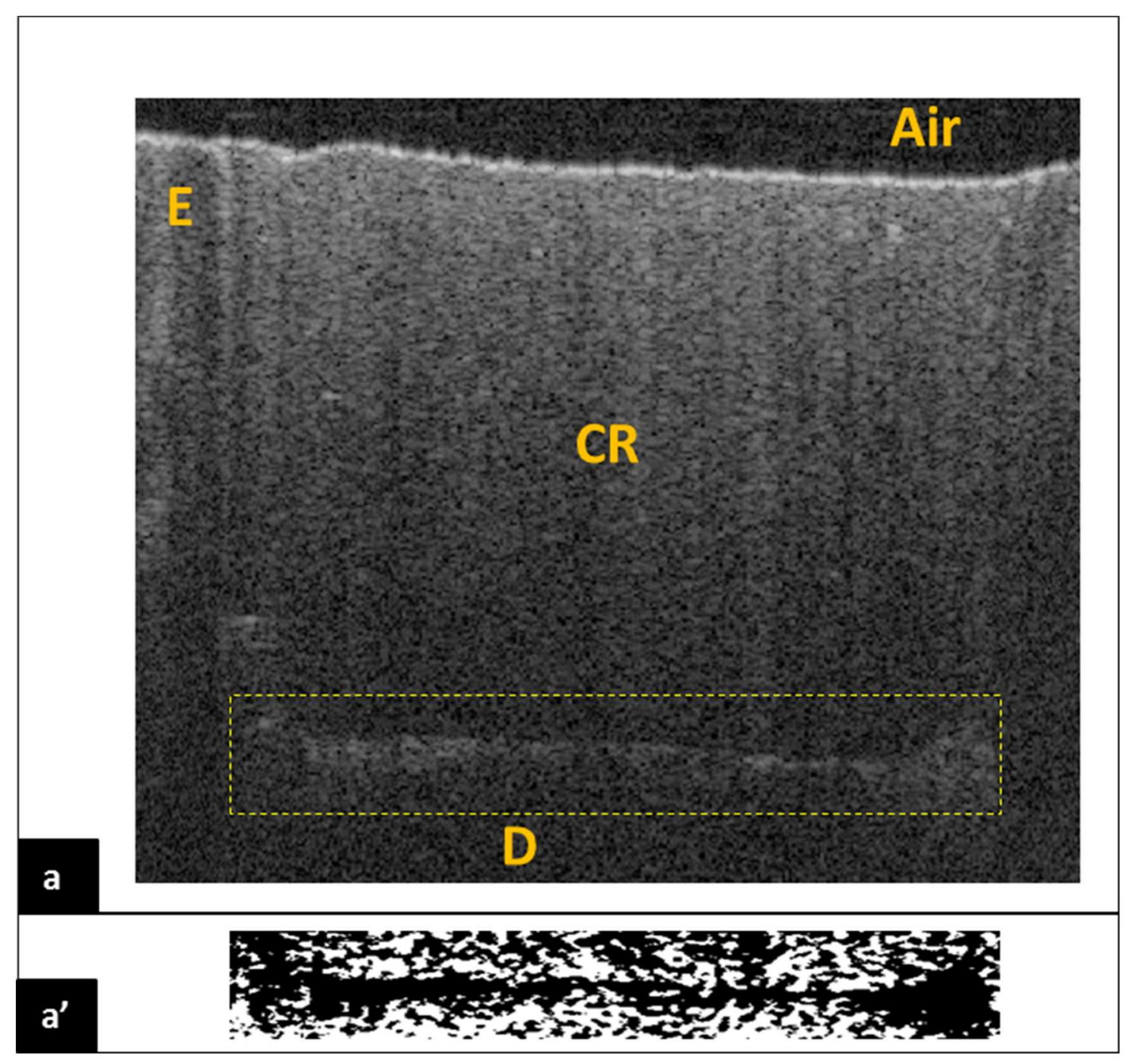

Figure 5. Representative B-scan for PL-HRV group. in (a). (a') is a binary image for the dotted box in (a) at the cavity floor. The cavity floor in (a) showed high signal intensity in a form of a continues band of bright pixels that were corresponding to the dark pixels in (a'). CR: Composite resin, E: Enamel, D: Dentin.

\section{Discussion}

Many studies investigated composite adaptation and gap formation using compressed air, dye penetration, bacteria, radioactive markers, micro-CT and ultrasounds 
[26,27]. However, these methods are either destructive, invasive or require prolong time for acquisition and processing. Moreover, although ultrasound is a non-invasive imaging technique, the resolution of the system is lower than the OCT that makes the OCT system superior from several prospective $[6,7,28]$.

CP-OCT system differs from swept-source OCT in that it includes a second polarizer to remove the mirror-like reflection. This setup made CP-OCT system a useful tool for demineralization and remineralization studies but not for gap detection studies. Hence, to broaden the application of CP-OCT, immersion in metallic contrasting agent to intensify the gap appearance was necessary to improve the gap reflection under the composite restoration [24].

Ammoniacal silver-nitrate solution had been widely employed in nanoleakage studies. The silver ions in the solution can easily penetrate the interfacial spaces and transform into silver grains upon light exposure. Upon CP-OCT imaging, areas with heavy accumulation of silver scattered the light into different direction reflection and produced diffuse reflections (bright pixels). While the areas that devoid of silver particles were not showing any considerable reflection in a form of bright pixels [24].

C-factor is defined as the ratio of bonded surface area to unbonded surface area of a restoration [29]. It is considered an influencing factor on composite adaptation against contraction stresses. Many studies showed a positive correlation between debonding and the C-factor with highest C-factor being in class-I cavities [30].

In this study, the highest gap \% was seen in PL-HRV group followed by SE-ESA, PL-ESA, SE-HRV, respectively. The last three groups; SE-ESA, PL-ESA, SE-HRV, showed less than $10 \%$ of gap, which indicate strong adaptation and high adhesive 
performance correspondingly. It can be inferred from the results that gap formation is a multifactorial defect and depends on different factors other than C-factor such as the type of composite and adhesive system.

SE adhesive is a two-step self-etch adhesive that contains MDP monomer, which has a high binding affinity to hydroxyapatite [31]. Nurrohman et al. reported that when using such self-etch adhesives in dentin, the acidic functional monomers cause incomplete demineralization of the apatite to form a strong chemical bond as well as acid resistance apatite rich zone beneath the hybrid layer (ABRZ) [31]. In addition, bond strength and durability studies attributed the superior performance of this adhesive to the MDP monomer [32].

In this study, the adaptation of SE-ESA group was significantly lower than SEHRV group. Unlike HRV composite, the high filler loading in ESA composite are expected to reduce the polymerization shrinkage. However, this high filler loading had raised the contraction stresses in high $\mathrm{C}$-factor cavities, which could negatively affect the composite adaptation and explain the obtained results.

PL adhesives is a fluoride-releasing adhesive that contains 3D-SR functional monomer. The strong bond created by the 3D-SR functional monomer contribute to the adhesive bond longevity [33]. Moreover, the fluoride content in this adhesive would be responsible of creation of the ABRZ [34].

It is known that the weakest point in a restoration is the adhesive interface. The results in this study showed restoration adaptation of PL-ESA group was improved when the bonded resins were from the same manufacturer. This finding is supported by a report that showed a significant increase in the bond strength when the composite was repaired 
with a composite from the same manufacturer [35]. This would be attributed to the compatibility issue between the copolymers of the bonded materials, which explain the obtained results in PL-ESA in comparison to PL-HRV. It is worth mentioning that both SE-ESA and PL-ESA groups shared the same composite and differed in the adhesive. Although many reports presented the superior performance of two-step self-etch adhesives over one-step [24,36,37], the obtained results showed no significant difference between SEESA and PL-ESA groups. It seems that the co-polymers compatibility between the bonded resins in PL-ESA had played a significant role in improving PL performance and gap reduction under the restoration. On the contrary, the mismatch between the co-polymers of the restoration in PL-HRV could explain the lower performance in this group.

\section{Conclusions}

Within the limitation of this in vitro study, it can be concluded that composite microleakage can be effectively assessed non-destructively using CP-OCT. Other than composite filler loading and adhesive formula, the interactions of the adhesive and composite co-polymers have great influence on composite adaptation.

\section{Acknowledgment}

This study was supported by Faculty of Dentistry, King Abdulaziz University, Jeddah, Saudi Arabia.

\section{Conflicts of Interest:}

The authors declare no conflict of interest. 


\section{Reference}

1. Bakhsh, T.A.; Sadr, A.; Shimada, Y.; Khunkar, S.; Tagami, J.; Sumi, Y. Relationship between non-destructive OCT evaluation of resins composites and bond strength in a cavity. Proceedings of BiOS Phtonic West SPIE, Lasers in Dentistry, USA, 2012; 8208. doi:10.1117/12.908365.

2. Estafan, D.; Agosta, C. Eliminating microleakage from the composite resin system. Gen Dent 2003, 51, 506-509. https://pdfs.semanticscholar.org/de83/9b2958fe406c9ff276d88d005d9f1ab0d87f.pdf

3. Bagis, Y.H.; Baltacioglu, I.H.; Kahyaogullari, S. Comparing microleakage and the layering methods of silorane-based resin composite in wide Class II MOD cavities. Oper Dent 2009, 34, 578-585, doi:10.2341/08-073-LR.

4. Sadr, A.; Shimada, Y.; Mayoral, J.R.; Hariri, I.; Bakhsh, T.A.; Sumi, S.; Tagami, J. Swept source optical coherence tomography for quantitative and qualitative assessment of dental composite restorations. Proceedings of BiOS Phtonic West SPI, Lasers in Dentistry XVII, San Francisco, California, USA, 2011;7884. doi:10.1117/12.877351.

5. Lammeier, C.; Li, Y.; Lunos, S.; Fok, A.; Rudney, J.; Jones, R.S. Influence of dental resin material composition on cross-polarization-optical coherence tomography imaging. J Biomed Opt 2012, 17, 106002, doi:10.1117/1.JBO.17.10.106002.

6. Bakhsh, T.A.; Sadr, A.; Shimada, Y.; Tagami, J.; Sumi, Y. Non-invasive quantification of resin-dentin interfacial gaps using optical coherence tomography: validation against confocal microscopy. Dent Mater 2011, 27, 915-925, doi:10.1016/j.dental.2011.05.003.

7. Huang, D.; Swanson, E.A.; Lin, C.P.; Schuman, J.S.; Stinson, W.G.; Chang, W.; Hee, M.R.; Flotte, T.; Gregory, K.; Puliafito, C.A., et al. Optical coherence tomography. Science 1991, 254, 1178-1181, doi: 10.1126/science.1957169.

8. Colston, B.W., Jr.; Everett, M.J.; Da Silva, L.B.; Otis, L.L.; Stroeve, P.; Nathel, H. Imaging of hard- and soft-tissue structure in the oral cavity by optical coherence tomography. Appl Opt 1998, 37, 3582-3585, doi:10.1364/AO.37.003582.

9. Feldchtein, F.; Gelikonov, V.; Iksanov, R.; Gelikonov, G.; Kuranov, R.; Sergeev, A.; Gladkova, N.; Ourutina, M.; Reitze, D.; Warren, J. In vivo OCT imaging of hard and soft tissue of the oral cavity. Opt Express 1998, 3, 239-250, doi: 10.1364/OE.3.000239.

10. Wang, X.J.; Milner, T.E.; de Boer, J.F.; Zhang, Y.; Pashley, D.H.; Nelson, J.S. Characterization of dentin and enamel by use of optical coherence tomography. Appl Opt 1999, 38, 2092-2096, doi: 10.1364/AO.38.002092.

11. Lenton, P.; Rudney, J.; Chen, R.; Fok, A.; Aparicio, C.; Jones, R.S. Imaging in vivo secondary caries and ex vivo dental biofilms using cross-polarization optical coherence tomography. Dent Mater 2012, 28, 792-800, doi:10.1016/j.dental.2012.04.004.

12. Rasmussen, K.; Reilly, C.; Li, Y.; Jones, R.S. Real-time imaging of anti-biofilm effects using CP-OCT. Biotechnol Bioeng 2016, 113, 198-205, doi:10.1002/bit.25701.

13. Shimada, Y.; Sadr, A.; Burrow, M.F.; Tagami, J.; Ozawa, N.; Sumi, Y. Validation of swept-source optical coherence tomography (SS-OCT) for the diagnosis of occlusal caries. J Dent 2010, 38, 655-665, doi:10.1016/j.jdent.2010.05.004.

14. Makishi, P.; Shimada, Y.; Sadr, A.; Tagami, J.; Sumi, Y. Non-destructive 3D imaging of composite restorations using optical coherence tomography: Marginal adaptation of selfetch adhesives. $J$ Dent 2011, 39, 316-325, doi: 10.1016/j.jdent.2011.01.011. 
15. Alsayed, E.Z.; Hariri, I.; Sadr, A.; Nakashima, S.; Bakhsh, T.A.; Shimada, Y.; Sumi, Y.; Tagami, J. Optical coherence tomography for evaluation of enamel and protective coatings. Dent Mater J 2015, 34, 98-107, doi:10.4012/dmj.2014-215.

16. Schneider, H.; Park, K.-J.; Häfer, M.; Rüger, C.; Schmalz, G.; Krause, F.; Schmidt, J.; Ziebolz, D.; Haak, R. Dental Applications of Optical Coherence Tomography (OCT) in Cariology. Applied Sciences 2017, 7, 472, doi:10.3390/app7050472.

17. Bakhsh, T.A.; Sadr, A.; Mandurah, M.M.; Shimada, Y.; Zakaria, O.; Tagami, J. In situ characterization of resin-dentin interfaces using conventional vs. cryofocused ion-beam milling. Dent Mater 2015, 31, 833-844, doi:10.1016/j.dental.2015.04.010.

18. Marghalani, H.Y.; Bakhsh, T.; Sadr, A.; Tagami, J. Ultramorphological assessment of dentin-resin interface after use of simplified adhesives. Oper Dent 2015, 40, E28-39, doi:10.2341/13-373-L.

19. Marghalani, H.Y.; Bakhsh, T.; Sadr, A.; Tagami, J. Ultra-structural characterization of enamel-resin interface using FIB-TEM technology. J Adhes Sci Technol 2014, 28, $1005-$ 1019, doi:10.1080/01694243.2014.882073.

20. Van Meerbeek, B.; Yoshihara, K.; Yoshida, Y.; Mine, A.; De Munck, J.; Van Landuyt, K.L. State of the art of self-etch adhesives. Dent Mater 2011, 27, 17-28, doi:10.1016/j.dental.2010.10.023.

21. Yazici, A.R.; Yildirim, Z.; Ertan, A.; Ozgunaltay, G.; Dayangac, B.; Antonson, S.A.; Antonson, D.E. Bond strength of one-step self-etch adhesives and their predecessors to ground versus unground enamel. Eur J Dent 2012, 6, 280-286.

22. Turkistani, A.; Almutairi, M.; Banakhar, N.; Rubehan, R.; Mugharbil, S.; Jamleh, A.; Nasir, A.; Bakhsh, T. Optical Evaluation of Enamel Microleakage with One-Step SelfEtch Adhesives. Photomed Laser Surg 2018, 0, doi:10.1089/pho.2018.4441.

23. Turki, A.B.; Malek, E.; Shahad, A.; Nadiyah, A.; Atheer, A.; Alaa, T.; Muhannad, S.; Zuhair, S.N. Optical Quantification of Microgaps at Dentin-Composite Interface. Biomed Phys Eng Express 2018, 4, 045030 doi:10.1088/2057-1976/aac9f2.

24. Bakhsh, T.A.; Altouki, N.H.; Baeesa, L.S.; Baamer, R.A.; Alshebany, R.M.; Natto, Z.; Nasir, A.; Turkistani, A.; Hasanain, F.; Naguib, G.H. Effect of self-etch adhesives on the internal adaptation of composite restoration: a CP-OCT Study. Odontology 2018, doi:10.1007/s10266-018-0381-2.

25. Bakhsh, T.A.; Bakry, A.S.; Mandurah, M.M.; Abbassy, M.A. Novel evaluation and treatment techniques for white spot lesions. An in vitro study. Orthod Craniofac Res 2017, 20, 170-176, doi:10.1111/ocr.12193.

26. Alani, A.H.; Toh, C.G. Detection of microleakage around dental restorations: a review. Oper Dent 1997, 22, 173-185.

27. de Santi Alvarenga, F.A.; Pinelli, C.; Monteiro Loffredo Lde, C. Reliability of marginal microleakage assessment by visual and digital methods. Euro J Dent 2015, 9, 1-5, doi:10.4103/1305-7456.149628.

28. Fujimoto, J.G.; Pitris, C.; Boppart, S.A.; Brezinski, M.E. Optical coherence tomography: an emerging technology for biomedical imaging and optical biopsy. Neoplasia 2000, 2, 9-25.

29. Feilzer, A.J.; De Gee, A.J.; Davidson, C.L. Setting stress in composite resin in relation to configuration of the restoration. J Dent Res 1987, 66, 1636-1639, doi:

$10.1177 / 00220345870660110601$. 
30. dos Santos, G.O.; da Silva, A.H.; Guimaraes, J.G.; Barcellos Ade, A.; Sampaio, E.M.; da Silva, E.M. Analysis of gap formation at tooth-composite resin interface: effect of Cfactor and light-curing protocol. J Appl Oral Sci 2007, 15, 270-274, doi: 10.1590/S167877572007000400006.

31. Nurrohman, H.; Nikaido, T.; Takagaki, T.; Sadr, A.; Ichinose, S.; Tagami, J. Apatite crystal protection against acid-attack beneath resin-dentin interface with four adhesives: TEM and crystallography evidence. Dent Mater 2012, 28, e89-98, doi:10.1016/j.dental.2012.04.025.

32. Inoue, S.; Koshiro, K.; Yoshida, Y.; De Munck, J.; Nagakane, K.; Suzuki, K.; Sano, H.; Van Meerbeek, B. Hydrolytic stability of self-etch adhesives bonded to dentin. J Dent Res 2005, 84, 1160-1164, doi:10.1177/154405910508401213.

33. Yoshida, Y.; Yoshihara, K.; Nagaoka, N.; Hanabusa, M.; Matsumoto, T.; Momoi, Y. Xray diffraction analysis of three-dimensional self-reinforcing monomer and its chemical interaction with tooth and hydroxyapatite. Dent Mater J 2012, 31, 697-702, doi: 10.4012/dmj.2012-074.

34. Tsujimoto, M.; Nikaido, T.; Inoue, G.; Sadr, A.; Tagami, J. Ultrastructural observation of the acid-base resistant zone of all-in-one adhesives using three different acid-base challenges. Dent Mater J 2010, 29, 655-660, doi: 10.4012/dmj.2010-004.

35. Forsten, L.; Valiaho, M.L. Transverse and bond strength of restorative resins. Acta Odontol Scand 1971, 29, 527-537, doi: 10.3109/00016357109026331.

36. Ishikawa, A.; Shimada, Y.; Foxton, R.M.; Tagami, J. Micro-tensile and micro-shear bond strengths of current self-etch adhesives to enamel and dentin. Am J Dent 2007, 20, 161166.

37. Yuan, Y.; Shimada, Y.; Ichinose, S.; Sadr, A.; Tagami, J. Effects of dentin characteristics on interfacial nanoleakage. J Dent Res 2007, 86, doi:10.1177/154405910708601016. 